\title{
Use of Brick Aggregate in Standard Concrete and Its Performance in Elevated Temperature
}

\author{
Gopinandan Dey and Joyanta Pal
}

\begin{abstract}
By far the most common coarse aggregate used in concrete is obtained from natural rock, but type of rock suitable for concrete making is not available everywhere. In Tripura a north-eastern state of India brick aggregate concrete are used conventionally for ordinary concrete due to scarcity of aggregate from natural source. Due to advancement of concrete technology and to fulfill the durability requirement it necessitated to use standard concrete, for which only stone aggregate is used, as a result, cost of construction has been skyrocketed as these are transported from other states.

Making good quality concrete with finest sand (grading zone -IV as per Indian code IS:383-1970) is itself a challenge, moreover there is unavailability of natural coarse aggregate locally. Therefore, in this paper a concerted effort has been made to check the feasibility of use of brick aggregate made of locally available brick in standard concrete (M25 to M55 as per IS:456-2000). High water absorption ( $12 \%$ to $20 \%$ by mass) of brick aggregate is a major problem to use it in the actual work, thus an attempt has been made to suggest a realistic solution for real field application. An experimental study has been conducted to check various strength parameters, workability and fire resistance of brick aggregate concrete. It is observed that standard concrete can be made with crushed brick aggregate which are also having very good heat resistance upto a temperature of $600^{\circ} \mathrm{C}$.
\end{abstract}

Index Terms-standard concrete, brick aggregate, fire resistance, water absorption.

\section{INTRODUCTION}

Concrete is produced by mixing cement, sand, coarse aggregate and water to produce a material that can be molded into almost any shape. The major volume of concrete is filled with aggregate. Aggregate inclusion in concrete reduces its drying shrinkage and improves many other properties. Aggregate is also the least expensive per weight unit, put it makes the most amount of the weight. It is costly to transport so local sources are needed, but due to geographical constraint this is not available at all places, therefore it necessitates finding other sources and alternatives from local sources.

In eastern and north eastern states of India and Bangladesh where natural rock deposits are scarce, burnt clay bricks are used as an alternative source of coarse aggregate. In these places of India brick aggregate are traditionally used as coarse aggregate. The use and performance of concrete made with broken brick as coarse aggregate are quite extensive and satisfactory for ordinary concrete. Clay and silt alongwith

Manuscript received February 5, 2013; revised June 6, 2013. This work was supported by All India Council for Technical Education (AICTE), a statutory body of Govt. of India.

The authors are with the Department of Civil Engineering, Natinal Institute of Technology Agartala, Tripura, India (e-mail: gopinita@ymail.com,joyantanita@yahoo.com). appropriate quantity of sand can be burnt in its natural form as is done in brick-making and the product may be a source of coarse aggregate for concrete. Also in brick-making, a large number of bricks are rejected due to nonconformity with the required specifications. One such major nonconformity is the distorted form of brick produced due to the uneven temperature control in the kiln. These rejected bricks can also be a potential source of coarse aggregate [1].

Akhtaruzzaman and Hasnat [2] investigated the various engineering properties of concrete using crushed brick as coarse aggregate. Khaloo [3] studied the properties of concrete using crushed clinker brick as coarse aggregate. In both the above-mentioned studies, investigations were also done by comparing the properties of brick aggregate concrete with those for stone aggregate concrete. Rashid et al. [1] investigated the properties of higher strength concrete with brick aggregate. On the other hand, studies were done by Mansur et al. [4] comparing the properties of stone aggregate concrete with those of equivalent brick aggregate concrete obtained by replacing stone with an equal volume of crushed brick, everything else remaining the same.

Cachim [5] studied the mechanical properties brick aggregate concrete by partial replacement of natural stone aggregate by brick aggregate and it was found that upto $15 \%$ replacement there is no reduction of strength. Debieb and Kenai [6] showed that it is possible to produce concrete containing crushed bricks (coarse and fine) with characteristics similar to those of natural aggregate concrete provided that the percentage of brick aggregates is limited to 25 and $50 \%$ for the coarse and fine aggregate respectively.

Apart from strength parameter in ambient temperature Khalaf and DeVenny [7] studied the thermal properties of brick aggregate concrete and it was found that brick aggregate concrete perform similar and even better than granite aggregate concrete in elevated temperature.

\section{RESEARCH SIGNIFICANCE}

Notwithstanding extensive use of brick aggregate concrete in this regions and the apparent satisfactory performance of the existing structure constructed with brick aggregate concrete, no systematic investigation was conducted and properly documented for the brick aggregate found in this region. In most of the construction upto last decade mostly nominal mix concrete were used based on perception and accumulation of experience. With the advancement of the concrete technology and to fulfill the durability requirement M25 (28 days characteristic compressive strength $25 \mathrm{MPa}$ when tested on $150 \mathrm{~mm}$ cube) and higher grade of concrete is generally used in most of the construction now a days, thus there is a complete shift of trend to the use of stone aggregate 
instead of brick aggregate in concrete, as there is lack of experimental study or separate codal recommendation regarding the use of brick aggregate in standard concrete (M25 to M55 as per IS:456-2000). Consequently, in recent days construction cost of the concrete structure increased manifold. Therefore, a systematic investigation is required regarding the feasibility of use of crushed brick as aggregate as the strength of the brick available in this region is much lower than that used by other previous researchers. High water absorption of the brick aggregate in the range of 12 to $20 \%$ by dry weight of brick aggregate also causes a serious problem to use it in the work, though the earlier researchers used SSD aggregate in their investigation, but in the reality it is not possible to make the aggregates SSD. Apart from this sand available locally is also very fine grained having FM value less than 2.00. Moreover durability is another aspect which is also greatly emphasized in the present code. In a real structure temperature may rise to a large extent due to fire, therefore study on durability against elevated temperature also may be undertaken.

\section{MATERIALS USED IN THE INVESTIGATION}

\section{A. Cement}

The cement used was ordinary Portland cement (OPC) of 43 grades conforming to IS: 8112-1989.

Fine aggregate

One type of fine aggregate was used throughout the experimental work so as to keep the fine aggregate variable constant. The sand was collected from a local small stream from the flowing water which is generally used in most of constructions in near vicinity of this stream. The grain size of sand from all the sources in Tripura is more or less similar.

The sieve analysis was carried out in accordance with IS: 383-1970 for the fine aggregate. The results of the grading fits within the limits set out in IS: 383-1970 for grading zone -IV, which is the finest among all the grading zones as per Indian standard. The fineness modulus of the sand found to be 1.97 and specific gravity 2.43 . The silt and clay content of the fine aggregate is $2 \%$.

\section{B. Bricks}

Only one type of unused clay bricks of $240 \times 115 \times 70 \mathrm{~mm}$ working sizes was used in the investigation before the bricks were crushed down into a coarse aggregate, their uniaxial compressive strength was recorded for comparison with the aggregate produced by crushing them down to coarse aggregate. The compressive strength of the whole brick is found to be $12.75 \mathrm{MPa}$.

\section{Brick Aggregate}

Full bricks were crushed to $40 \mathrm{~mm}$ nominal size aggregate as per Indian code IS: 383-1970, the grading curve for the same is shown in Fig. 2. It was observed that crushing of bricks mechanically with jaw crusher produce flaky and elongated aggregate, so breaking of brick was done manually with hammer which produced angular aggregate. Tests of mechanical and physical properties were done on the aggregates as per IS:2386-1963, it was found that crushing value of the aggregate $32 \%$ and water absorption $13.25 \%$, The fineness modulus of the brick aggregate found to be 7.47 and specific gravity 1.82 .

\section{Admixtures}

A superplasticizing admixture BASF Rheobuild 1100i (SNF) as per IS:9103- 1999 was added to the mixing water used, in order to improve workability and to study the effect of admixtures on the properties of fresh and hardened concrete.

\section{TEST PROGRAM FOR THE EXPERIMENT}

\section{A. Mix Design}

The basic guideline for mix design of concrete as per the Indian code IS: 10262-2009 was followed. According to the codal guideline saturated and surface dry (SSD) aggregates are used and in case of aggregate either moist or dried adjustment is done accordingly. Most of the previous researchers who did the work on brick aggregate used SSD aggregate, but in real project work it will be next to impossible to prepare SSD aggregate. If the adjustment is done for very dry aggregate adding extra water for absorption at that case total quantity of water in the mix will be higher than the calculated amount because during the process of setting only 75 to $85 \%$ water will be absorbed by the aggregate and remaining water in the mix will result increase of $\mathrm{w} / \mathrm{c}$ ratio because subsequently most of the pores will be sealed by the matrix and the water will remain within the cement grains. In consequence of this there will be loss of strength. On the other hand if the water is mixed for absorption only for the setting period it will produce a concrete of desired workability in the fresh state and in some cases decrease of $\mathrm{w} / \mathrm{c}$ ratio leading to increased strength. A realistic value of three minute's water absorption was taken as standard in this investigation as it was seen that the rate of water absorption in first few minutes is very high and then after the curve becomes very flat. Rate of water absorption of brick aggregate is shown in Fig. 1. Coarse aggregate and fine aggregate used in the mix was partially dried and therefore in the calculation of mix design necessary adjustment was made for fine aggregate.

\section{B. Mixing of Concrete and Workability Test}

The $24 \mathrm{~h}$ water absorption capacity of the brick aggregate was $13.25 \%$, an in situ test of the water absorption for three minutes were checked and which was found to be $6.5 \%$ by weight of the existing condition of the aggregate, therefore necessary adjustment was made for these quantity of water. In Fig. 1 rate of water absorption of dry aggregate has been presented. For preparing the mix first coarse aggregate and $80 \%$ of the total water had been placed in the mixer and rotated for two minutes to allow the coarse aggregate to absorb water, then fine aggregate, cement and remaining quantity of water mixed with admixture were fed in the mixer and rotated for two minutes more and the mix concrete was discharged on a metal tray. Slump test was conducted for measuring the workability of the concrete.

\section{Test for Strength of Concrete}

6(six) Nos of $150 \mathrm{~mm}$ cube were prepared as per the mix design following the above mentioned procedure for compressive strength test, moreover 12(twelve) Nos cube of similar dimension for test of strength at different temperature and 3(three) Nos prism of $100 \mathrm{~mm}$ x $100 \mathrm{~mm}$ x $500 \mathrm{~mm}$ were 
prepared for flexure test. All the samples were kept in the molds for 24 hours and thereafter those samples were demolded and placed in the curing tank for 28 days in ambient temperature. All the samples were taken out of the curing tank before testing and wiping the surface necessary test for uniaxial compressive strength was done in a compression testing machine of $2000 \mathrm{kN}$ capacity. The flexural tests by two points loading were done in a flexural testing machine of $100 \mathrm{kN}$ capacity.

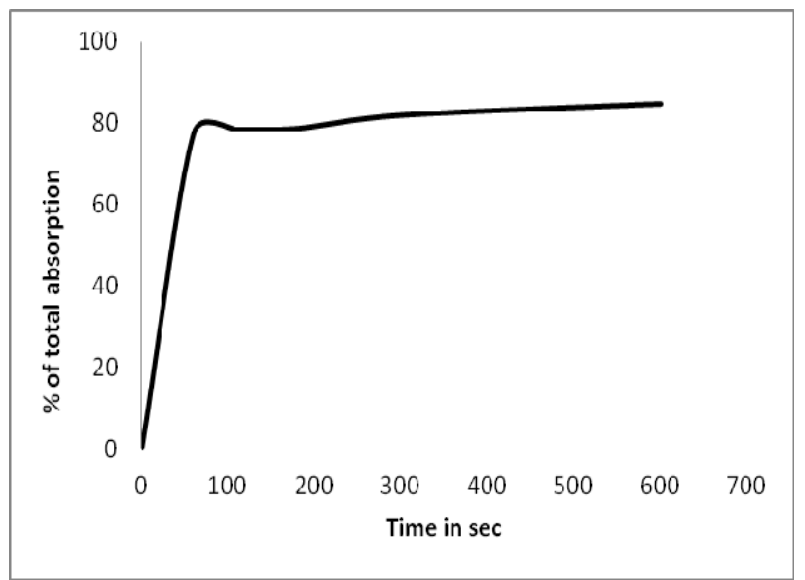

Fig. 1. Rate of water absorption of brick aggregate

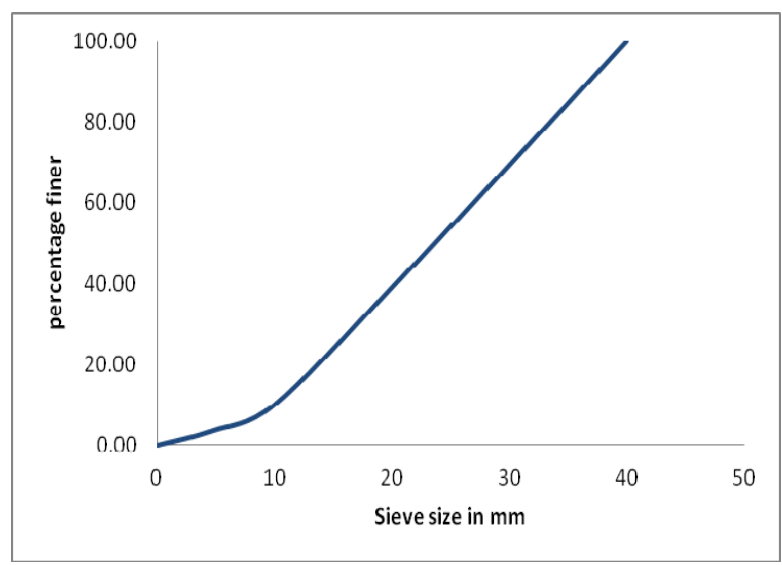

Fig. 2. Grading of coarse aggregate

\section{High Temperature Test}

Concrete is noncombustible and in general as a material has a good ability to withstand fire. The type of aggregate influences the response of concrete to high temperature. The duration reinforced concrete elements in structures last under a fire are decided by the dimensions of the elements cross sections and cover to the reinforcements [BS 8110: Part 1 (BSI 1997) and ACI 318 (ACI 2002)].

The high temperature test is designed to determine the ability and duration of all the concretes produced in this investigation to maintain compressive strength when exposed to elevated temperatures. Twelve $150 \mathrm{~mm}$ test cubes were taken from each mix for strength tests at different temperatures. Three cubes for each temperature were used from each different mix to test for compressive strength. The test cubes were placed in an electrically operated temperature controlled furnace and subjected to designate temperatures of $200,400,600$, and $800^{\circ} \mathrm{C}$ for a period of $2 \mathrm{~h}$. The cubes were tested for compressive strength in a digital compression testing machine of $2000 \mathrm{kN}$ capacity making those cool to the ambient temperature after removal from the furnace. Temperature effect on compressive strength of concrete as originally proposed by Neville is shown in Fig. 3.

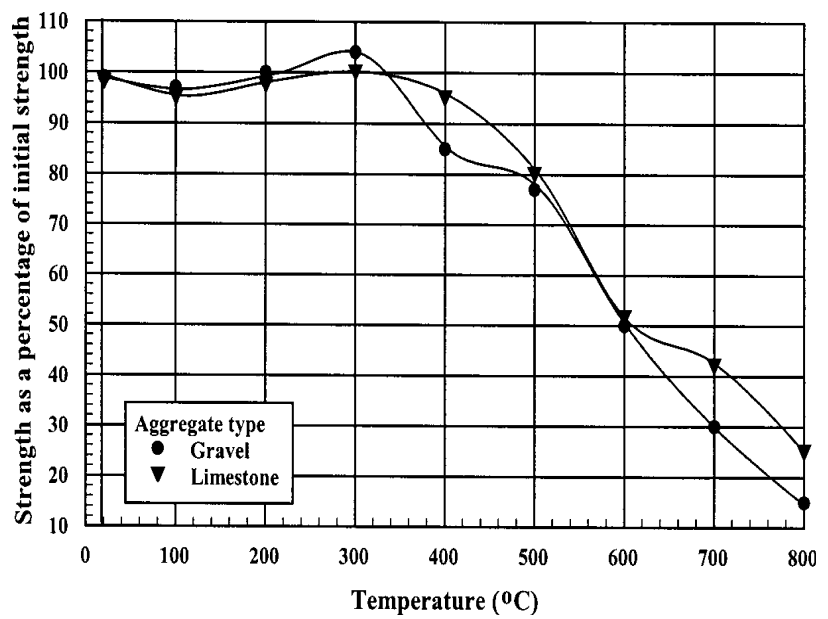

Fig. 3.Temperature effect on compressive strength of concrete [7]

\section{RESUlTS AND DiscUSSION}

The compressive strength, flexural strength and workability results for the concretes produced with different $\mathrm{w} / \mathrm{c}$ ratios are presented in Table I. From the experimental results of the strength parameter it is seen that within the limitation of Indian code provision of maximum cement content $450 \mathrm{~kg} / \mathrm{m}^{3}$ upto strength of nearly $40.00 \mathrm{MPa}$ can be achieved easily which may be corresponding to M30 concrete considering a standard deviation of 5 . On the other hand lower strength such as M20 and M25 may easily be obtained with much less quantity of cement. Adequate workability similar to pumpable concrete can also be obtained with the use of super plasticizing Admixture. The density of the concrete obtained is also in the range of 19750 to $20000 \mathrm{~N} / \mathrm{m}^{3}$ which is nearly $85 \%$ of the concrete prepared from stone aggregate. Flexural strength achieved is also higher than the Indian code recommendation of $0.7 \sqrt{ } \mathrm{fck}$. The strength of the concrete in elevated temperature is also presented in Table II. It is observed that there is a gradual increase of strength of concrete upto temperature of $600^{\circ} \mathrm{C}$ thereafter there is a drastic fall of compressive strength which becomes nearly 60 to $70 \%$ of the original 28 days strength.

TABLE I: Mix DETAILS AND STRENGTH OF CONCRETE

\begin{tabular}{|c|c|c|c|c|c|c|c|c|}
\hline $\begin{array}{l}\mathrm{W} / \mathrm{C} \\
\text { ratio }\end{array}$ & $\begin{array}{l}\text { Water } \\
(\mathrm{kg})\end{array}$ & $\begin{array}{c}\text { Cement } \\
(\mathrm{kg})\end{array}$ & $\begin{array}{c}\text { Coarse aggregate } \\
(\mathrm{kg})\end{array}$ & $\begin{array}{c}\text { Fine aggregate } \\
(\mathrm{kg})\end{array}$ & $\begin{array}{c}\text { Superplasticizer } \\
(\mathrm{kg})\end{array}$ & $\begin{array}{c}\text { Slump } \\
(\mathrm{mm})\end{array}$ & $\begin{array}{c}\text { Compressive strength } \\
(\mathrm{MPa})\end{array}$ & $\begin{array}{c}\text { Flexural strength } \\
(\mathrm{MPa})\end{array}$ \\
\hline 0.45 & 171 & 380 & 857 & 564 & 3.3 & 135 & 28.67 & 4.40 \\
\hline 0.40 & 171 & 430 & 850 & 534 & 3.3 & 125 & 31.94 & 4.84 \\
\hline 0.35 & 157 & 450 & 870 & 522 & 4.5 & 140 & 38.72 & 5.13 \\
\hline 0.38 & 171 & 450 & 842 & 529 & 3.3 & 80 & 39.67 & 5.60 \\
\hline
\end{tabular}


TABLE II: STRENGTH OF CONCRETE IN ELEVATED TEMPERATURE

\begin{tabular}{|cccccc|}
\hline $\begin{array}{c}\text { W/C } \\
\text { ratio }\end{array}$ & $\begin{array}{c}\text { Compressive Strength at } \\
200^{\circ} \mathrm{C}(\mathrm{MPa})\end{array}$ & $\begin{array}{c}\text { Compressive Strength at } \\
400^{\circ} \mathrm{C}(\mathrm{MPa})\end{array}$ & $\begin{array}{c}\text { Compressive Strength at } \\
600^{\circ} \mathrm{C}(\mathrm{MPa})\end{array}$ & $\begin{array}{c}\text { Compressive Strength at } \\
800^{\circ} \mathrm{C}(\mathrm{MPa})\end{array}$ & $\begin{array}{c}\text { Compressive Strength at } \\
\text { ambient temperature }(\mathrm{MPa})\end{array}$ \\
\hline 0.45 & 35.74 & 35.35 & 36.51 & 20.38 & 28.67 \\
0.40 & 26.40 & 28.96 & 35.86 & 19.03 & 31.94 \\
0.35 & 42.95 & 41.53 & 43.30 & 28.23 & 38.72 \\
0.38 & 41.35 & 43.78 & 41.52 & 28.23 & 39.67 \\
\hline
\end{tabular}

\section{CONCLUSION}

1) Crushed bricks can be used satisfactorily to produce $M 25$ and M30 concrete keeping water cement ratio in the range of 0.35 to 0.40 .

2) Sufficient workability upto the level of pumpable concrete can also be achieved by suitably using the superplasticizer within a range of $0.8 \%$ to $1 \%$ by weight of cement.

3) Flexural strength also can be obtained as per the codal requirement and even more.

4) For mix design it is not required to make the aggregate SSD either by presoaking or providing additional water for total water absorption, rather water absorption for 3 minutes may be referred as the absorption for dry aggregate.

5) In high temperature the performance up to $600^{\circ} \mathrm{C}$ is even better than ambient temperature for an exposure period of 2 hours.

6) Fine aggregate having very low fineness modulus is also fit for producing standard concrete.

7) Durability aspect of concrete made of brick aggregate may further be studied for permeability and freeze and thaw effect.

8) Further study is required for brick aggregate made from parent brick of different strength.

\section{REFERENCES}

[1] M. A. Rashida, T. Hossaina, and M. A. Islam, "Properties of higher strength concrete made with crushed brick as coarse aggregate," Journal of Civil Engineering (IEB), vol. 37, no. 1, pp. 43-52, 2009.
[2] A. A. Akhtaruzzaman and A. Hasnat "Properties of concrete using crushed brick as aggregate," Concrete International, vol. 5, no. 2, pp. 58-63, 1983.

[3] A. R Khaloo, "Properties of concrete using crushed clinker brick as coarse aggregate," ACI Materials Journal, vol. 91, no. 2, pp. 401-407, 1994.

[4] M. A. Mansur, T. H. Wee, and L. S. Cheran,. "Crushed bricks as coarse aggregate for concrete," ACI Materials Journal, vol. 96, no. 4, pp. 478-484, 1999.

[5] P. B. Cachim, "Mechanical properties of brick aggregate concrete," Construction and Building Materials, vol. 23, pp. 1292-1297, 2009.

[6] F. Debieb and S. Kenai "The use of coarse and fine crushed bricks as aggregate in concrete," Construction and Building Materials, vol 22, pp.886-893, 2008.

[7] F. M. Khalaf and A. S. DeVenny, "Performance of brick aggregate concrete at high temperatures," Journal of Materials in Civil Engineering, ASCE, vol. 16, no 6, pp. 556-565, 2004.

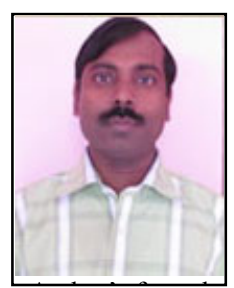

Gopinandan Dey is an assistant professor of NIT Agartala. He was born in 1972. He obtained the B.E degree in civil engineering from Tripura Engineering College under Tripura University, India in 1994 and M.Tech Degree in Structural engineering from NIT Agartala, India in 2010. He is awarded with Gold Medal in M.Tech. His field of research interest lies in concrete technology.

He has a long stint of experience over 16 years as an academician and Engineer. He has publication in International Journal in the field of concrete technology. He attended many conferences in India and abroad.

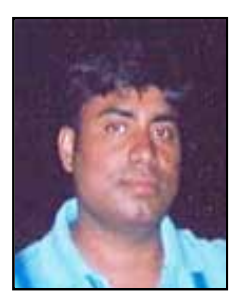

Joyanta Pal is an assistant professor of NIT Agartala He was born in 1974.He obtained the B.Tech degree in civil engineering from Regional Enginnering College Hamirpur, India in 1997 and M.Tech Degree in structural engineering from NIT Agartala, India in 2010. His field of research interest lies in concrete technology.

He has a long stint of experience over 10 years as an academician and Engineers. 